\title{
Competição de gramáticas na aquisição da flexão de número pelas crianças brasileiras: Um estudo experimental sobre a produção infantil ${ }^{1}$
}

\section{Grammar competition in the acquisition of number inflection by Brazilian children: An experimental study on child production}

\author{
Marina Maia Reis ${ }^{2}$ \\ Universidade Estadual de Campinas, Brasil
}

\begin{abstract}
RESUMO
Este estudo objetivou investigar a aquisição da marca morfofonológica de plural no SN e no verbo pelas crianças brasileiras, sob a luz da teoria de P\&P e da proposta de competição de gramáticas. Para tal, realizou-se um experimento de produção eliciada. Os resultados obtidos sugerem tendências distintas para a concordância nominal e verbal. Propõe-se que a variação entre os padrões de concordância no SN seja um reflexo da aquisição de duas gramáticas, com parâmetros formatados de maneira distinta, para a marcação de plural na língua. Já a variação observada no verbo parece relacionar-se ao processo de aquisição, sugerindo a aquisição de apenas uma gramática (com a marcação de plural explícita) ao fim do processo.
\end{abstract}

PALAVRAS-CHAVE:

Concordância variável. Aquisição da linguagem. Variação linguística. Competição de gramáticas; Princípios e parâmetros.

Recebido em: 15/05/2020

Aceito em: 03/08/2020

\section{ABSTRACT}

This study aimed to investigate the acquisition of the plural morphophonological mark in the NP and in the verb by Brazilian children, under the light of the P\&P theory and the grammar competition proposal. To this end, an elicited production experiment was carried out. The results obtained suggest different trends for nominal and verbal agreement. It is proposed that the variation between the agreement patterns in the NP is reflection of the acquisition of two grammars, with parameters set in a different way, for the plural marking in the language. The variation observed in the verb seems to be related to the acquisition process, suggesting the acquisition of only one grammar (with the explicit plural marking) at the end of the process..

\section{KEYWORDS:}

Variable Agreement. Language acquisition. Linguistic variation. Grammar competition. Principles and parameters.

\footnotetext{
${ }^{1}$ Este trabalho é parte da dissertação de mestrado da autora, que teve suporte do CNPq (processo n 130423/2018-1).

${ }^{2}$ E-mail: marinamreis@outlook.com | ORCID: 0000-0001-5010-4180.
} 


\section{Introdução}

Neste trabalho, é enfocada a aquisição de um fenômeno em variação na fala dos brasileiros: a concordância de número. Assim, serão apresentados, aqui, os resultados encontrados em um experimento de produção eliciada, conduzido com crianças com idades entre 3 e 5 anos adquirindo Português Brasileiro (doravante, PB). Com esse experimento, buscou-se identificar de que maneira a concordância de número é realizada na produção infantil, a partir da observação da realização da concordância de número entre os itens do SN e nos verbos, a fim de compreender um pouco melhor como a variação presente no input pode influenciar o processo de aquisição de língua materna pela criança.

Diversos trabalhos dentro da Sociolinguística Variacionista têm demonstrado a existência de dois padrões para a realização da concordância de número nas produções linguísticas dos falantes de PB (Naro; Lemle, 1976; Lemle; Naro, 1977; Naro, 1981; Scherre; Naro, 2006; Brandão; Vieira, 2012; Mendes; Oushiro, 2015, entre outros). No primeiro padrão, todos os elementos da sentença que são passíveis de serem flexionados em número recebem a marca morfofonológica de plural, como em (1); já no segundo padrão, apenas alguns (ou mesmo um) dos elementos recebem a marca de plural, como em (2) abaixo. Por haver uma reiteração da marca de plural entre os elementos da sentença, chamamos o tipo de concordância observado em (1) de concordância redundante (ou de concordância padrão). Por outro lado, uma vez que essa reiteração não acontece em sentenças como a apresentada em (2), esse tipo de concordância é chamado de concordância não redundante (ou de concordância não padrão). Desse modo, a possibilidade de alternância entre a presença e a ausência da marca morfofonológica de plural nos itens do SN e no verbo ficou conhecida na literatura como Concordância Variável.

(1) As meninas bonitas chegaram tarde.

(2) As menina $\varnothing$ bonita $\varnothing$ chegou tarde.

O fenômeno da Concordância Variável em PB foi - e ainda tem sido - bastante estudado pelos sociolinguistas. Os trabalhos indicam que esse fenômeno é influenciado tanto por condicionadores linguísticos quanto por condicionadores extralinguísticos. Entre os condicionadores linguísticos, estão a posição linear e relativa da palavra, a classe da palavra, o contexto fonológico, a saliência fônica, o paralelismo, a animacidade do núcleo do SN, a posição do sujeito em relação ao verbo e o tipo de concordância no sujeito. Já entre os extralinguísticos, 
observou-se que o grau de escolaridade, o nível socioeconômico e o sexo/gênero do falante são fatores que influenciam no tipo de concordância utilizado por ele. ${ }^{3}$ Entre os fatores que parecem estar relacionados a esse fenômeno na língua, interessam, para este estudo, a saliência fônica do nome e o grau de escolaridade e o nível socioeconômico do falante, uma vez que estes foram fatores controlados no experimento realizado.

Em PB, nomes com plural regular são aqueles em que o plural é realizado apenas com o acréscimo do morfema -s (e.g., casa-casas). Contudo, esse morfema pode ser realizado de outras maneiras na língua. Ele também pode ser marcado por: (i) /-Is/, como em mês-meses; (ii) /-õjs/, como em barão-barões; (iii) /-ãjs/, como em pão-pães; e (iv) mudanças em uma das vogais da raiz, como em ovo-ovos. Os nomes em que o plural é realizado de forma regular são definidos como nomes menos salientes, enquanto nomes em que o plural ocorre seguindo os padrões em (i), (ii), (iii) e (iv) são considerados como nomes mais salientes. O que os estudos têm sugerido é que parece haver uma preferência pela ausência do morfema de plural em itens menos salientes que em itens mais salientes (Antonio, 2007; Brandão; Vieira, 2012; Dias; Fernandes, 2000; Fiamengui, 2011; Guy, 1981; Lopes, 2001; Scherre, 1988; Oushiro, 2015 apud Mendes; Oushiro, 2015). Com essa questão em mente, este estudo também buscou investigar se a saliência fônica do nome se mostraria um fator relevante para a determinação do padrão utilizado pelas crianças testadas.

No que tange aos fatores extralinguísticos, a variável mais relevante para descrever a forte estratificação social observada nas comunidades linguísticas é o grau de escolaridade do falante (Mendes; Oushiro, 2015). A maioria dos estudos nos quais esse fator foi analisado exibiu um padrão sistemático de grande tendência a uso de marcas de plural explícitas por falantes com graus de escolaridade mais altos (Scherre, 1988; 1991; Salomão, 2010; DIAS; Fernandes, 2000; Oushiro, 2015; Naro; Scherre, 2013; Rodrigues, 1987; Pereira, 2004; Rubio; Gonçalves, 2012; Ziles; Maia; Silva, 2000 apud Mendes; Oushiro, 2015; Brandão; Vieira, 2012). Oushiro (2015 apud Mendes; Oushiro, 2015), em uma comparação entre grau de escolaridade e nível socioeconômico dos falantes, observou que a classe social do falante parece ser mais importante no uso variável da concordância, tanto entre os itens do SN quanto entre sujeito e verbo. Por essa razão, considerou-se importante levar em consideração esses fatores neste estudo.

Tendo em vista que os falantes produzem tanto enunciados com concordância redundante

\footnotetext{
${ }^{3}$ Para uma descrição detalhada dos condicionadores que influenciam a Concordância Variável em PB, cf. Mendes e Oushiro (2015).
} 
quanto com concordância não redundante, uma criança exposta ao PB encontra no input evidência ambígua no que diz respeito à realização de plural nessa língua. Ainda não se sabe como exatamente a variação afeta a aquisição, e, embora haja na literatura trabalhos investigando a aquisição de fenômenos em variação nas línguas, eles são poucos (Miller; Schmitt, 2009; 2010; 2012a; 2012b; Castro; Ferrari-Neto, 2007; Gomes et al., 2011; Molina, 2018; Jakubów, 2018; entre outros). Estudos em diversas línguas demonstraram que as crianças tendem a reproduzir a variação observada no input, exibindo, em suas produções linguísticas, as formas em variação encontradas na fala dos adultos (Lessa-de-Oliveira, 2005; Miller; Schmitt, 2009; 2010; 2012a; 2012b; Gomes et al., 2011; Molina, 2018; Reis, 2020). Assim, a questão que se coloca para os pesquisadores interessados em compreender questões relacionadas ao processo de aquisição de língua materna em contexto de variação é, então, a seguinte: visto que a criança se apoia nos dados presentes no input para identificar as propriedades da língua a que está exposta e marcar os parâmetros da Gramática Universal (GU) de acordo com a formatação paramétrica observada na língua-alvo, o que acontece quando o input disponível fornece evidência ambígua acerca de uma determinada propriedade da língua para ela? Entender de que maneira a variação pode interferir no desenvolvimento linguístico infantil e no resultado final da aquisição é de crucial interesse para as pesquisas que investigam a aquisição em contexto de variação - inclusive para a pesquisa desenvolvida aqui.

Para fundamentar as discussões realizadas aqui, assume-se o arcabouço teórico da Teoria de Princípios e Parâmetros (Chomsky, 1981) e a proposta de competição de gramáticas, de Yang (2002). Assim, entendo o processo de aquisição de língua materna como um processo natural e espontâneo. Seguindo a proposta de Yang (2002), também se assume que: (i) a aquisição da linguagem proceda a partir de competição de gramáticas; e que (ii) duas gramáticas, com um mesmo parâmetro formatado de maneira distinta, possam coexistir na mente do falante ao fim do processo de aquisição. Os resultados encontrados neste estudo corroboram tanto para (i) quanto para (ii).

Desse modo, este trabalho está organizado como se segue: inicialmente, apresento, brevemente, os pressupostos veiculados pela Teoria de Princípios de Parâmetros (1981) e a proposta de competição de gramáticas de Yang (2002); em seguida, explicito a metodologia e os resultados do experimento conduzido neste estudo; na seção 3, demonstra-se de que maneira os resultados obtidos podem ser explicados com base na perspectiva assumida por Yang (2002), clarificando a proposta desenvolvida aqui para a aquisição da concordância de número em PB; 
finalmente, as considerações finais são tecidas.

\section{Princípios e Parâmetros e o Modelo Variacional}

Como mencionado, assumiu-se a Teoria de Princípios e Parâmetros (P\&P) (Chomsky, 1981) como base para este estudo. Sob a ótica dessa teoria, entende-se que todos os seres humanos nascem dotados de um dispositivo pré-programado para a aquisição de uma língua, dispositivo este que se materializa como a Gramática Universal (GU) do falante. Nessa perspectiva, a GU é definida como um dispositivo composto por vários subsistemas de princípios inatos (Chomsky, 1986a, p. 146), que guiam o processo de aquisição de língua materna. Assim, a Teoria de P\&P postula que todas as línguas compartilham princípios universais que as regem, e que muitos desses princípios exibem parâmetros atrelados a eles, que devem ser fixados durante o processo de aquisição da linguagem pela criança. A variação entre as línguas naturais está em um escopo paramétrico, i.e., "as línguas e dialetos variam porque os parâmetros podem ser diferentemente definidos conforme o 'input' da comunidade." (Kato, 1995, p. 67).

Yang (2002) propõe, com seu Modelo Variacional (Variational Model), uma abordagem que integra a teoria da GU e aprendizagem estatística para a aquisição da linguagem. Para o autor, o processo de aquisição de uma língua pela criança ocorreria por meio de gramáticas competindo. Yang assume a existência de um número finito de gramáticas humanas possíveis, limitadas pela GU, na mente do aprendiz. Tendo em vista a não-uniformidade e a gradualidade da linguagem infantil, observadas durante o desenvolvimento linguístico da criança, ele introduz noções estatísticas no modelo proposto. Seguindo a base do pensamento evolucionário darwiniano, o autor concebe o processo de aquisição da linguagem como uma população de gramáticas, com pesos relativos, que competem em um processo selecionista. As gramáticas que receberem mais recompensas que punições diante dos dados dispostos no input estarão mais proeminentes no espaço de hipóteses da criança (Yang, 2002, p. 32) ${ }^{4}$. Assim, a(s) gramática(s) que, ao fim do processo de aquisição, tiver(em) sido mais recompensada(s) será(ão) a(s) gramática(s) adquirida(s) pelo falante.

É bastante claro que o input desempenha um papel fundamental para a aquisição de uma língua. Entende-se que os princípios e os parâmetros limitem o espaço de hipóteses que o aprendiz pode formular durante a aquisição, mas os dados disponíveis no input a que a criança é

\footnotetext{
${ }^{4}$ Os termos recompensar e punir são utilizados metaforicamente pelo autor, para se referir aos pesos relativos atribuídos às gramáticas existentes nos indivíduos com base nos dados no input.
} 
exposta é que determinarão de que maneira os parâmetros deverão ser fixados para que a gramática infantil alcance, ao fim do processo, a formatação observada na gramática da línguaalvo. A presença de variação no input pode torná-lo inconsistente, fazendo com que haja evidência ambígua para o aprendiz. Como diversos trabalhos demonstram, a presença de duas formas em variação em uma comunidade de fala caracteriza, muitas vezes, um estágio que antecede uma mudança linguística (Coelho et al., 2010). Autores que assumem um arcabouço teórico gerativista defendem que a mudança linguística recai sobre a aquisição (Kroch, 2003; Avelar, 2006; Lightfoot, 2010; entre outros). Nesse sentido, Avelar (2006) põe em jogo a validade do termo "mudança em progresso" dentro de uma abordagem desenvolvida à luz da Teoria de Princípios e Parâmetros. O linguista afirma que:

[...] a rigor, não existe coisa alguma que possa ser chamada de mudança no interior de uma gramática nuclear. A mudança lingüística que interessa ao gerativista é aquela que resulta do fato de um indivíduo, no processo de aquisição, formar a sua gramática nuclear com propriedades diversas às da gramática pertencente à geração que the fornece os dados primários. Não faz sentido, sob essa ótica, falar de uma mudança em progresso ocorrendo na gramática internalizada. (Avelar, 2006, p. 138)

Sob essa ótica, a variação observada em uma comunidade linguística poderia ser de dois tipos: (i) no nível da comunidade, ela pode dizer respeito a formatações paramétricas distintas nas gramáticas de falantes de diferentes gerações (Kroch, 1994); (ii) no nível individual, a variação só poderia existir se pensada em termos de gramática nuclear e periférica (Kato, 2005; Avelar, 2006). ${ }^{5}$ Tanto (i) quanto (ii) parecem não capturar algumas características do processo de mudança linguística no contexto real. Por um lado, o que é proposto em (i) dá conta de explicar a variação na fala de indivíduos de gerações distintas, mas, por outro, não consegue explicar como um mesmo falante pode exibir variação em suas produções linguísticas. A possibilidade (ii), embora dê conta, em alguma medida, da variação no nível individual, não consegue explica-la em contexto de variação estável, por exemplo. A disputa entre gramática nuclear e gramática periférica abrange, de maneira satisfatória, apenas fenômenos relacionados à variação no nível lexical - como o caso de ter e haver, discutido em Avelar (2006) - ou, quando no nível paramétrico, dá conta somente da alternância entre uma forma usual e outra, de fato, bem menos recorrente nas produções dos falantes - como parece ocorrer com o preenchimento do sujeito em

\footnotetext{
${ }^{5}$ Como esta não será a discussão em que me aprofundarei neste trabalho, ela é apenas mencionada brevemente aqui. Para uma explicitação mais aprofundada desses conceitos e da proposta de Avelar (2006) para ter e haver em construções existenciais, cf. Avelar (2006).
} 
determinados contextos na fala dos brasileiros, conforme Kato (2005) propõe.

A proposta de competição de gramáticas, nos termos de Yang (2002), abre espaço para uma terceira possibilidade para se tratar da variação linguística. Assumindo que o processo de aquisição ocorra através de gramáticas competindo, um indivíduo pode ter mais de uma gramática estabilizada, com parâmetros formatados de maneira oposta, ao fim do processo de aquisição, caso haja evidência suficiente no input. Isso significa dizer que, diante de um input ambíguo ou inconsistente - ou seja, com dados que podem servir como evidência para duas marcações paramétricas opostas -, mais de uma gramática pode ocupar um espaço proeminente no espaço de hipóteses infantil. Se essas gramáticas seguem sendo "recompensadas" até o fim do processo de aquisição, o falante terá adquirido duas gramáticas. Essa terceira hipótese captura melhor tanto o próprio processo de aquisição de uma língua, independente de se em um contexto em que um input é consistente ou se é ambíguo, quanto a própria gradualidade da mudança linguística. Por essa razão, considero a proposta de Yang (2002) mais adequada para explicar o fenômeno analisado aqui, i.e., a aquisição da concordância de número em PB, visto que os dados encontrados na pesquisa desenvolvida neste estudo parecem estar muito mais de acordo com os pressupostos assumidos pelo autor que com os que são veiculados pelas propostas dispostas em (i) e (ii). Essa discussão será retomada na seção 3. Antes, contudo, apresentarei os resultados obtidos no experimento de produção realizado.

\section{Experimento - Produção eliciada}

Como mencionado, um estudo experimental foi conduzido com crianças adquirindo PB, a fim de verificar como a concordância de número é produzida pelas crianças brasileiras, tanto no âmbito do SN quanto no verbo. Buscou-se investigar também se um condicionador linguístico - a saliência fônica do nome - e condicionadores extralinguísticos - o grau de escolaridade e o nível socioeconômico dos pais, medidos pelo tipo de escola frequentada pela criança - influenciariam no padrão de concordância utilizado pela criança. Para tal, aplicou-se um experimento de produção eliciada com crianças monolíngues adquirindo PB.

\subsection{Design do experimento}

A variável tomada como dependente no experimento realizado foi o tipo de concordância no $S N$ e no verbo - redundante $(R)$ vs. não redundante $(N R)$. As variáveis independentes 
controladas para a concordância entre sujeito e verbo foram: (i) a idade do participante (3, 4 ou 5 anos); e (ii) o tipo de escola frequentada pelo participante (Pública vs. Privada). Para o SN, foram variáveis independentes controladas: (i) a saliência fônica do nome (saliente vs. não saliente); (ii) a idade do participante (3, 4 ou 5 anos); e o (iii) tipo de escola frequentada pelo participante (Pública vs. Privada).

A partir das variáveis independentes selecionadas para o SN, o experimento contava com dois tipos de respostas esperadas para os estímulos apresentados, conforme os exemplos abaixo:

\section{Esperada Não Saliente (ENS):}

Diante da apresentação dos estímulos visuais que se referiam a nomes não salientes, era esperado que as crianças produzissem sentenças do tipo: "As bolinha(s) amarela(s) está/estão na caixa grande e as bolinha(s) verde(s) está/estão na caixa pequena."

\section{Esperada Saliente (ES):}

Diante da apresentação dos estímulos visuais que se referiam a nomes salientes, era espero que as crianças produzissem sentenças do tipo: "As flor(es) vermelha(s) está/estão na caixa grande e as flor(es) verde(s) está/estão na caixa pequena."

Assim, as possíveis ocorrências nas produções infantis diante dos estímulos apresentados eram as seguintes:

- Para a concordância no SN:

- ENS Redundante: As bolinhas amarelas.

○ ENS Não Redundante: As bolinha(s/ $\varnothing)$ amarela(s/ $\varnothing)$.

- ES Redundante: As flores vermelhas.

○ ENS Não Redundante: As flor(es/ $\varnothing)$ vermelha(s/Ø).

- Para a entre sujeito e verbo:

○ Redundante: As bolinhas amarelas/flores vermelhas estão na caixa grande.

○ Não Redundante: As bolinha(s/ $\varnothing)$ amarela(s/ $\varnothing) / f l o r(e s / \varnothing)$ vermelha(s/ $\varnothing)$ está na caixa grande.

\subsection{Método}

\subsubsection{Participantes}


Este experimento foi aplicado com 75 crianças, com idades entre 3 e 5 anos, matriculadas em duas escolas da rede privada e em uma escola da rede pública, localizadas em um bairro periférico da cidade de Juiz de Fora/MG. Das crianças testadas, 55 são alunos matriculados em escola privada, e 20, em escola pública. As produções de 10 crianças, que não compreenderam a tarefa proposta ou não se sentiram confortáveis em realiza-la, não puderam ser consideradas para a análise, por não haver nenhuma ocorrência de plural na fala desses participantes. Além disso, 7 dos participantes testados não chegaram ao fim da tarefa: alguns por terem se cansado e outros por se mostrarem muito dispersos durante a realização da atividade proposta. Seus dados, contudo, não foram descartados, visto que todos produziram, em alguma medida, as estruturas esperadas (i.e., flexão de plural nos itens do SN e/ou no verbo) durante a tarefa, mesmo não tendo sido expostos a todos os estímulos experimentais. A tabela abaixo sumariza as informações concernentes aos participantes que tiveram seus dados analisados neste estudo:

Tabela 1 - Número de crianças testadas no experimento de produção por idade para cada uma das escolas.

\begin{tabular}{|cccc|}
\hline & \multicolumn{2}{c|}{ Escola Privada } & Escola Pública \\
\cline { 2 - 4 } $\begin{array}{c}\text { Idade das } \\
\text { Crianças }\end{array}$ & $\mathbf{P 1}$ & $\mathbf{P 2}$ & Pública \\
& & & xxx \\
& 7 crianças & 3 crianças & 10 crianças \\
& 10 crianças & 9 crianças & 9 crianças \\
4 anos & 8 crianças & 9 crianças & 19 crianças \\
5 anos & 25 crianças & 21 crianças & \\
Total: & & &
\end{tabular}

Além disso, antes de ser aplicado com o grupo experimental de crianças, aplicou-se o experimento com um grupo controle de adultos, no qual as condições experimentais criadas para as crianças foram reproduzidas. O experimento foi realizado com 15 adultos, recrutados na Universidade Federal de Juiz de Fora (UFJF).

\subsubsection{Materiais}

O experimento foi composto por 18 estímulos - 8 experimentais (4 com nomes considerados salientes e 4 com nomes considerados não salientes); 8 distratores; e 2 que funcionaram como pré-teste, seguindo o padrão dos estímulos distratores. Como estímulos 
experimentais, o experimento contava com dois conjuntos de objetos, que apenas diferiam em sua cor. Esses objetos foram divididos em (i) objetos que se referem a nomes não salientes nomes com plural regular, i.e., apenas com o acréscimo de $-s$ ao fim da palavra (bolinha/bolinhas); e (ii) objetos que se referem a nomes salientes - i.e., nomes que não têm plural regular na língua, contando com mais que apenas o acréscimo de $-s$ ao fim da palavra (flor/flores). Como estímulos experimentais, utilizaram-se conjuntos de objetos, para que fossem eliciadas as sentenças de interesse (sentenças com SN e verbo plurais). Já como estímulos distratores, utilizou-se apenas um objeto do conjunto. Assim, a única diferença entre os estímulos experimentais e distratores dizia respeito a sua quantidade. Além dos objetos que serviam como estímulos para eliciar a produção dos nomes esperados pelas crianças, o experimento contava com duas caixas, que diferiam apenas quanto ao seu tamanho - uma das caixas era grande e a outra pequena. Para tornar a tarefa mais lúdica para a criança, o experimento contava com dois fantoches, que eram manipulados por uma segunda investigadora durante a realização da atividade. Portanto, os materiais utilizados para a aplicação do experimento foram: os conjuntos de objetos que serviram como estímulos visuais para os participantes; duas caixas, nas quais os objetos eram colocados durante a realização do experimento; dois fantoches e um gravador de voz.

\subsubsection{Procedimento}

Para a aplicação do experimento com o grupo experimental, a criança era levada para uma sala com a presença de duas experimentadoras. Uma das experimentadoras ficava responsável por manusear os fantoches e a outra dava as instruções à criança durante o experimento. Antes do início da apresentação dos estímulos à criança, a experimentadora que conduzia o experimento apresentava os fantoches ao participante e ele era convidado a participar da brincadeira. Se a criança demonstrasse interesse, era dada sequência ao experimento, mas, caso a criança demonstrasse desinteresse, por qualquer motivo, ela era levada de volta para a sala de aula, e o experimento era encerrado. Uma vez que a apresentação dos fantoches tinha sido feita, a experimentadora vendava os olhos dos bonecos e dispunha os objetos que funcionaram como estímulos para a eliciação das construções analisadas diante da criança. Durante a aplicação do experimento, a experimentadora colocava um objeto de cada - para os estímulos distratores - ou cada conjunto de objetos - para os estímulos experimentais - em duas caixas, com tamanhos distintos (uma caixa grande e uma caixa pequena), e a tarefa da criança era, basicamente, contar quais objetos tinham sido colocados em cada caixa pela experimentadora. A experimentadora 
explicava, então, para o participante que sua tarefa durante a "brincadeira" era contar para um dos fantoches onde os objetos manuseados por ela seriam colocados a cada trial. Para tentar induzir a criança a produzir as sentenças da maneira esperada - i.e., sentenças do tipo "A bolinha amarela está na caixa pequena.", e não como "Na caixa pequena, tem uma bolinha amarela." -, a própria investigadora realizava a tarefa para exemplificar o que estava sendo proposto para o participante. É importante destacar que somente um objeto de cada cor era manuseado nesse momento inicial de exemplificação. Assim, todas as sentenças produzidas pela experimentadora exibiam sujeito e verbo no singular, para que não houvesse efeito de priming sobre a produção infantil.

Antes de partir para os estímulos experimentais, o participante era submetido a uma fase de pré-teste. Nessa fase, as crianças viam estímulos distratores (apenas um objeto de cada cor), seguindo o padrão dos estímulos manuseados na exemplificação realizada pela experimentadora. Finalmente, se a criança demonstrasse interesse na atividade proposta e tivesse um bom desempenho na fase de pré-teste, dava-se início à fase de teste. Nessa fase, a experimentadora manuseava dois objetos - um de cada cor - ou dois conjuntos de cinco objetos - cada conjunto de uma cor. A cada rodada, os objetos eram colocados em caixas, e a criança contava ao fantoche de sua preferência em qual das caixas eles haviam sido colocados. Os estímulos experimentais foram apresentados para os participantes aleatoriamente, mas um estímulo experimental nunca era apresentado depois de outro. Assim, sempre se tinha a ordem experimental-distrator.

Para a aplicação do experimento com o grupo controle de adultos, seguiu-se o mesmo procedimento realizado com as crianças, com exceção do uso de fantoches. Ao invés disso, era solicitado por uma das investigadoras (a que conduzia o experimento) que eles contassem onde os objetos eram colocados à outra experimentadora presente na sala, que se virava de costas e não via o que estava acontecendo. As sessões das crianças tinham duração de 15 a 20 minutos, e as dos adultos, em média de 5 minutos. Todas sessões foram gravadas em áudio e transcritas para análise posterior.

\subsection{Hipóteses e Previsões}

Visto que trabalhos sociolinguísticos indicam que os fatores grau de escolaridade e nível socioeconômico do falante influenciam no tipo de concordância utilizado por ele, a hipótese assumida aqui é de que crianças matriculadas nas escolas da rede privada exibirão mais ocorrências com concordância redundante em suas produções linguísticas que crianças 
matriculadas na escola da rede pública. Essa hipótese baseia-se no pressuposto adotado por Alves, Soares e Xavier (2014), de que escolas privadas agregariam indivíduos com nível socioeconômico mais alto, enquanto que escolas públicas (municipais e estaduais), indivíduos com nível socioeconômico mais baixo (apud Molina; Marcilese; Name, 2017). Com base na hipótese de pesquisa, prevê-se que: (i) a ausência da marca de plural será mais recorrente entre os itens do SN do que nos verbos (Scherre; Naro, 2006), uma vez que o uso de concordância não redundante nos verbos parece ser mais estigmatizado que no sintagma nominal ${ }^{6}$; (ii) as crianças exibirão variação entre a presença/ausência da marca morfofonológica de plural entre os itens do SN e no verbo, com índices de concordância redundante mais altos para os dois sintagmas (Molina, 2018; Jakubów, 2018); (iii) haverá influência do paralelismo formal sobre o padrão de concordância realizado (de acordo com o que há na literatura, espera-se que a ausência de marcas de plural no sujeito favoreça a ausência de marcas de plural no verbo - ex: As meninas bonitas saíram vs. As menina $\varnothing$ bonita $\varnothing$ saiu) para a concordância verbal (Brandão; Vieira, 2012; Molina, 2018); (iv) no que diz respeito à concordância nominal, nomes salientes (i.e., como plural irregular, como flor/flores) favorecerão o uso de concordância redundante se comparados aos nomes menos salientes (com plural regular, como bola/bolas) (Brandão; Vieira, 2012; Scherre; Naro, 2006; Mendes; Oushiro, 2015); (v) finalmente, adultos do grupo controle exibirão mais concordância redundante que as crianças, tanto no SN quanto no verbo (Molina, 2018).

\subsection{Resultados e discussão}

Uma vez que as gravações foram transcritas, buscaram-se por ocorrências de plural nas transcrições. Os dados encontrados foram transferidos para uma tabela do Excel e receberam tratamento estatístico. Todos os gráficos, tabelas e testes estatísticos apresentados aqui foram implementados com o software R, versão 3.6.1 (R Core Team, 2019).

Foram encontradas, no total, 2101 observações de plural na fala dos participantes do experimento de produção realizado neste trabalho. Dessas ocorrências, 300 foram observadas na fala dos adultos do grupo controle e 1801 na fala das crianças do grupo experimental, matriculadas nas escolas das redes pública e privada onde o experimento foi aplicado. Dessas

\footnotetext{
${ }^{6}$ É importante ressaltar que Brandão e Vieira (2012) encontraram índices mais altos de concordância não padrão em verbos de 3 a pessoa que nos itens do SN nas produções linguísticas de falantes de PB ( $8,9 \%$ no SN e $21,9 \%$ em verbos de 3 a p.). Contudo, parto do pressuposto de que, na fala dos brasileiros, os verbos exibem mais concordância padrão que os elementos presentes no SN, como encontrado nas amostras analisadas por Scherre e Naro (2006).
} 
ocorrências, 1770 foram tabuladas como esperadas ${ }^{7}$, sendo 264 casos encontrados nas produções dos adultos e 1506 casos encontrados na fala das crianças. Nas produções dos adultos, foram encontradas 260 ocorrências com concordância R (i.e., concordância redundante) (87\% dos casos) ${ }^{8}$ e 40 ocorrências com concordância NR (i.e., concordância não redundante) (13\% dos casos). Já nas produções infantis, foram encontradas 630 ocorrências com concordância R (35\% dos casos) e 1149 ocorrências com concordância NR (65\% dos casos). A distribuição das ocorrências com concordância R e NR, por grupo, idade do participante (para as crianças) e escola frequentada pelo participante (também para as crianças), encontram-se dispostas na tabela 2 abaixo. As proporções de ocorrências com concordância R e NR nos dados dos dois grupos são apresentadas na figura 1.

Tabela 2 - Frequência e proporção de ocorrências com concordância R e NR nas produções dos adultos e das crianças por tipo de escola e idade frequentada pelo participante.

Grupo /Tipo de escola/Idade

\begin{tabular}{ccc}
\cline { 2 - 3 } Adultos & NR & R \\
Criança/Privada/3 anos & $40(16 \%)$ & $213(84 \%)$ \\
Criança/Privada/4 anos & $121(78 \%)$ & $34(22 \%)$ \\
Criança/Privada/5 anos & $308(69 \%)$ & $139(31 \%)$ \\
Criança/Pública/4 anos & $194(57 \%)$ & $147(43 \%)$ \\
\hline
\end{tabular}

\footnotetext{
${ }^{7}$ Foram consideradas ocorrências esperadas todas as ocorrências com palavras que se referiam aos estímulos experimentais apresentados ao participante. Essa diferenciação entre esperada vs. não esperada é importante, principalmente, para os itens do SN, para que se pudesse avaliar a influência do fator saliência fônica do nome de maneira um pouco mais controlada. No entanto, também se utilizou dessa distinção para os verbos: verbos de cópula foram tabulados como esperados, enquanto verbos que se enquadram em outras categorias, como não esperados. Destaco que os testes estatísticos inferenciais foram aplicados apenas sobre os dados tabulados como esperados. Tendo-se em vista o que foi mencionado anteriormente, essa escolha metodológica se deu por dois motivos: (i) entre os itens do SN, para que fosse possível verificar a interferência da saliência fônica do nome pelo modelo estatístico utilizado, visto que as ocorrências tabuladas como esperadas foram as em que se observaram nomes que se referiam aos estímulos visuais utilizados pela investigadora durante a aplicação do experimento. Isso permitiu analisar o uso da marca de plural apenas em ocorrências com nomes controlados no experimento, o que é desejável para minimizar a interferência de fatores externos, como variação lexical e ocorrências com grau de saliência fônica distintos no nome utilizado pelo participante; e (ii) no verbo, para que apenas verbos de cópula fossem considerados pelo modelo estatístico gerado, já que o tipo de verbo também pode ser um fator que pode influenciar a variação na concordância entre sujeito e verbo.
}

${ }^{8}$ Todos os percentuais apresentados neste trabalho são aproximações dos percentuais encontrados nos resultados. 
Figura 1 - Proporção de tipo de concordância por grupo nos dados completos.

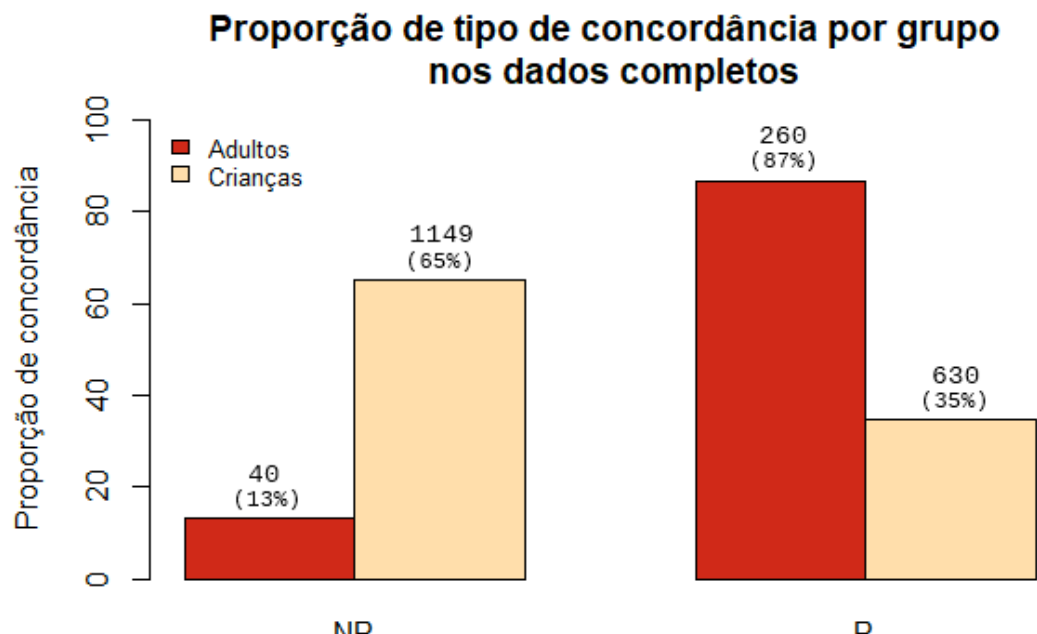

Tipo de Concordância

Nos dados dos adultos, todas as ocorrências com concordância NR foram encontradas entre os elementos do SN. Assim, não houve nenhum caso de concordância NR entre sujeito e verbo. Conforme demonstrado na figura 1, os índices de uso de concordância $\mathrm{R}$ na fala dos adultos foram consideravelmente superiores aos observados na produção infantil, como era esperado cf. previsão (v) acima. Já para as crianças, as ocorrências com concordância NR estão distribuídas nos dados dos dois sintagmas, sendo observadas tanto entre os itens do SN quanto no verbo. Como esperado, foi observada variação no tipo de concordância utilizado pelas crianças tanto no SN quanto no verbo. No entanto, houve mais concordância não redundante que redundante na produção infantil para os dois sintagmas, o que não está em consonância com a previsão (ii). Abaixo, estão dispostas as proporções de tipo de concordância por sintagma nos dados das crianças: 
Figura 2 - Proporção de tipo de concordância por sintagma nos dados das crianças.

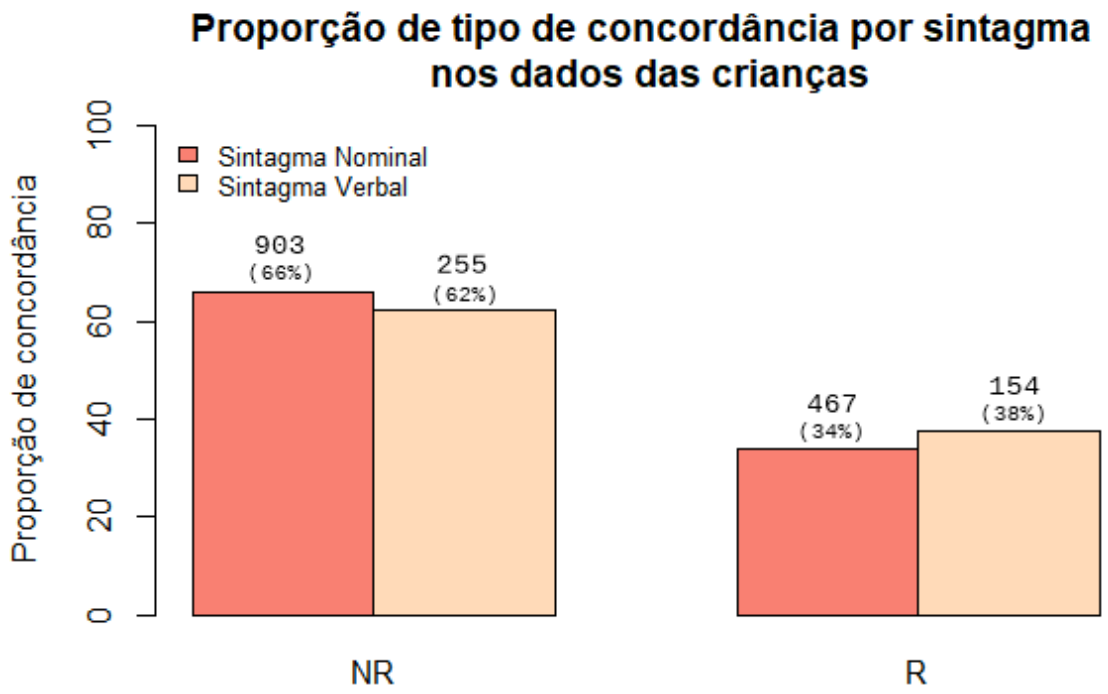

Tipo de Concordância

Como se pode perceber, a diferença entre as proporções de tipo de concordância para os dois sintagmas mostrou-se pequena, indo de encontro à previsão (i), de que haveria mais ocorrências com concordância não redundante no SN que nos verbos. Para confirmar que ela não foi estatisticamente significativa, aplicou-se um teste de qui-quadrado de Pearson, e, como esperado, o teste não resultou um valor de significância para esse fator $\left(\chi^{2}=1.6085(1), p=\right.$ 0.2047).

O tipo de escola frequentada pela criança também não foi um fator que se mostrou relevante para o tipo de concordância utilizado por ela. Esperava-se encontrar mais concordância NR na fala das crianças da escola da rede pública, mas os resultados encontrados não vão ao encontro dessa expectativa. Houve um pouco mais de concordância não redundante na fala das crianças da escola pública, mas essa diferença não foi significativa $\left(\chi^{2}=0.747476(1), p=0.3873\right){ }^{9}$

Como alguns fatores poderiam ser considerados só para o SN ou só para o verbo, optou-se por criar dois modelos de regressão logística de efeitos mistos - um para cada sintagma - para avaliar a relevância dos fatores analisados. No modelo gerado para o SN, foram considerados, em função da variável resposta tipo de concordância no SN, como efeitos fixos: saliência fônica do nome, tipo de escola frequentada pela criança e idade da criança (sem interação); e participante

\footnotetext{
${ }^{9}$ Este teste levou em consideração os dados completos das crianças, ou seja, ocorrências tabuladas como esperadas e ocorrências tabuladas como não esperadas, no SN e em verbos. Em seguida, são apresentados os resultados encontrados pelos modelos de regressão logística utilizados para o sintagma nominal e para o sintagma verbal, e os resultados encontrados para tipo de escola por sintagma separadamente.
} 
foi definido como efeito aleatório.

Tabela 3 - Análise, para o sintagma nominal, dos dados do experimento de produção das crianças - Valores estimados por regressão logística de efeitos mistos.

\begin{tabular}{lcccc}
\hline & Estimativa (logOdds) & Erro Padrão & valor-z & valor-p \\
\hline Intercepto & 2.5671 & 1.4599 & 1.758 & 0.0787 \\
Saliência Saliente & 0.6264 & 0.1600 & 3.914 & $9.07 \mathrm{e}-05$ \\
Escola pública & -0.1469 & 0.5177 & -0.284 & 0.7766 \\
Idade & -0.3837 & 0.3453 & -1.111 & 0.2665 \\
\hline
\end{tabular}

O modelo identificou a saliência fônica do nome como um fator relevante para o tipo de concordância entre os itens do SN, curiosamente, indicando uma tendência distinta da esperada cf. previsão (iv). Observou-se uma diferença significativa para nomes salientes em relação ao intercepto (concordância NR e nomes não salientes), i.e., nomes salientes parecem estar mais propensos a aparecer sem a marca morfofonológica de plural na fala das crianças que nomes não salientes $(p<0.001)$. Talvez o fator saliência fônica do nome não tenha estatuto nenhum para a criança. Além disso, houve menos uso de concordância NR por alunos da rede pública (indicado pelo sinal negativo na segunda coluna da tabela) em relação ao intercepto (concordância NR e escola privada), mas não houve diferença significativa entre escola pública e escola privada para os dados do SN $(p=0.7766)^{10}$. Por fim, o fator idade não se mostrou relevante para o modelo $(p=$ 0.2665), o que significa que crianças de 3 , de 4 e de 5 anos exibiram um padrão similar para a realização da concordância de número no SN. Os gráficos abaixo tornam visíveis os efeitos reportados pelo modelo.

\footnotetext{
${ }^{10}$ Os índices de uso de concordância R e NR no SN observados nos dados foram bastante próximos. Nas produções das crianças da escola da rede pública, 69\% das ocorrências observadas apresentou concordância NR e 31\% concordância R. Nos dados das crianças da rede privada, $68 \%$ das ocorrências exibiu concordância NR e 32\% concordância R.
} 
Figuras 3, 4 e 5-Gráficos para o SN, gerados a partir do modelo de regressão logística de efeitos mistos, com a proporção de concordância NR por tipo de escola frequentada pelo participante, por idade do participante e pela saliência do nome, respectivamente.
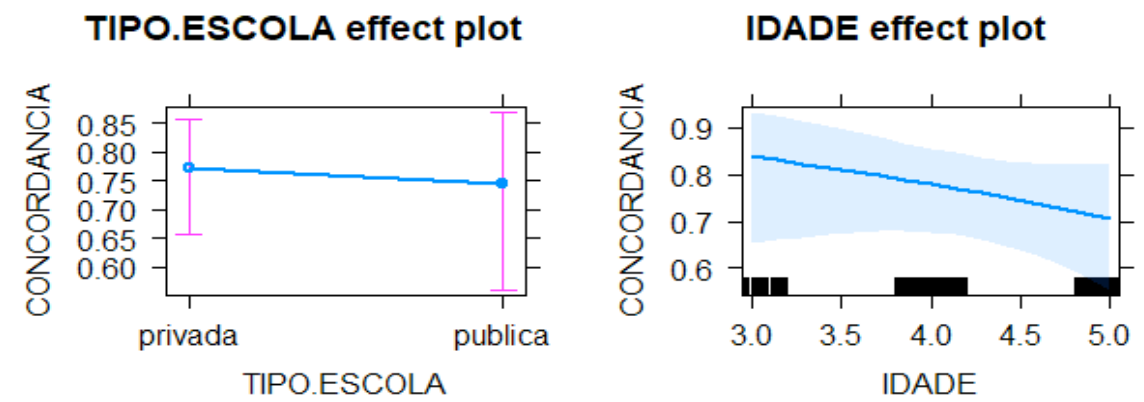

SALIENTE effect plot

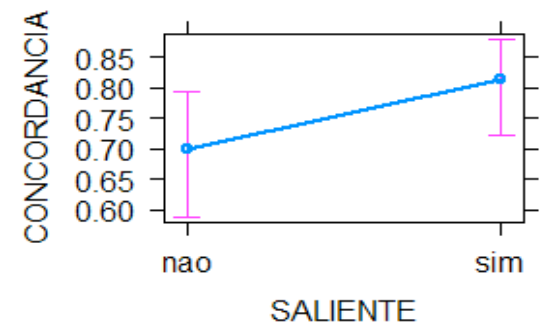

Já para a concordância entre sujeito e verbo, o modelo incluiu como efeitos fixos, também em função da variável resposta tipo de concordância no verbo, tipo de concordância no sujeito, posição do sujeito em relação ao verbo, tipo de escola frequentada pela criança e idade da criança (sem interação). Participante foi adicionado como efeito aleatório no modelo.

Tabela 4 - Análise, para o sintagma verbal, dos dados do experimento de produção das crianças - Valores estimados por regressão logística de efeitos mistos.

\begin{tabular}{lcccc}
\hline & Estimativa (logOdds) & Erro Padrão & valor-z & valor-p \\
\hline Intercepto & 12.9969 & 3.4830 & 3.731 & 0.00019 \\
Concordância Suj. R & -2.0919 & 0.4454 & -4.697 & $2.64 \mathrm{e}-06$ \\
Posição Sujeito Posposto & 0.5349 & 0.7808 & 0.685 & 0.49333 \\
Escola pública & 0.6398 & 0.8793 & 0.728 & 0.46683 \\
Idade & -2.4843 & 0.7719 & -3.218 & 0.00129 \\
\hline
\end{tabular}

O modelo identificou que houve diferença significativa para concordância $\mathrm{R}$ no sujeito em relação ao intercepto (concordância NR no verbo e concordância NR no sujeito). Como indicado na tabela acima, houve menos concordância NR nos verbos em ocorrências em que o sujeito exibia 
concordância $R$, e essa diferença foi estatisticamente significativa $(p<0,001)$. Assim, esse resultado está de acordo com a previsão (iii) disposta acima. Além disso, houve mais concordância NR para sujeitos pospostos ao verbo, mas a diferença entre sujeito posposto e o intercepto (concordância NR no verbo e sujeito anteposto) não foi considerada significativa pelo modelo ( $p=$ 0.49333). A diferença para escola pública em relação ao intercepto (concordância NR no verbo e escola privada) também não foi significativa $(p=0.46683)^{11}$. Finalmente, diferente do que foi observado para o SN, a idade da criança foi identificada como um fator relevante para a determinação do tipo de concordância no verbo $(p<0,05)$. Como demonstrado nos gráficos de efeitos dispostos abaixo - plotados a partir dos coeficientes gerados pelo modelo -, parece haver uma redução no uso de concordância NR nos verbos nas produções infantis em função do aumento da idade da criança. A figura abaixo sumariza as informações descritas aqui.

Figuras 6, 7, 8 e 9 - Gráficos para concordância entre sujeito e verbo, gerados a partir do modelo de regressão logística de efeitos mistos, com a proporção de concordância NR por tipo de escola frequentada pelo participante, por idade do participante, pelo tipo de concordância no sujeito e pela posição do sujeito em relação ao verbo, respectivamente.

TIPO.ESCOLA effect plot

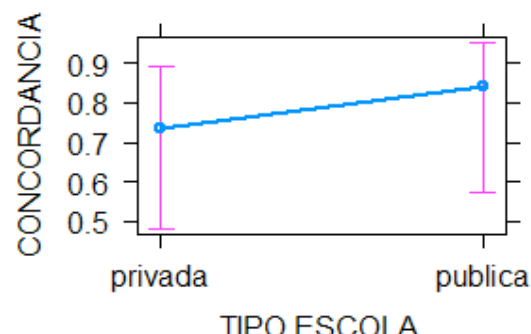

CONC.SUJ effect plot

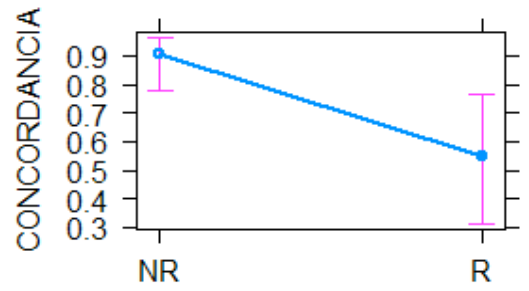

CONC.SUJ
IDADE effect plot

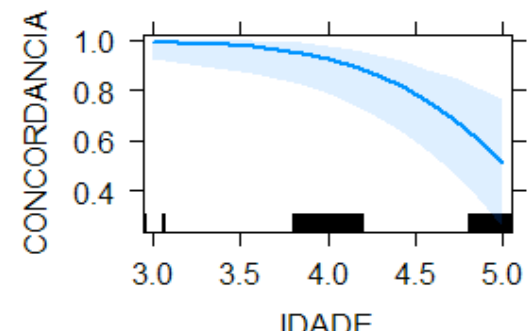

POS.SUJEITO effect plot

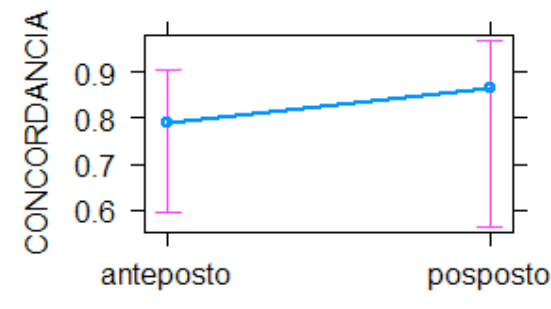

POS.SUJEITO

\footnotetext{
${ }^{11}$ Assim como para o SN, para a concordância entre sujeito e verbo, as proporções de uso de concordância R e NR exibiram valores próximos para crianças matriculadas em escolas das redes pública e privada. Nas produções das crianças da escola da rede pública, $63 \%$ das ocorrências observadas apresentou concordância NR e 37\% concordância R. Nos dados das crianças da rede privada, também $63 \%$ das ocorrências exibiu concordância NR e 37\% concordância R. Ressalto que houve pequenas diferenças nas casas decimais dos valores apresentados aqui e que as proporções estão todas aproximadas.
} 
Para verificar a distribuição dos dados no nível individual, a proporção de tipo de concordância por participante também foi analisada, conforme exibem os gráficos dispostos nas figuras 10 e 11 abaixo. Como se pode perceber, a maioria das crianças testadas exibiu variação em sua fala quando se tratava do SN, mas a variação identificada para a concordância entre sujeito e verbo foi bem menor no âmbito individual: a maioria das crianças ou só produziu concordância $R$ ou só produziu concordância NR.

Figura 10 - Proporção de tipo de concordância no SN por participante nos dados das crianças.

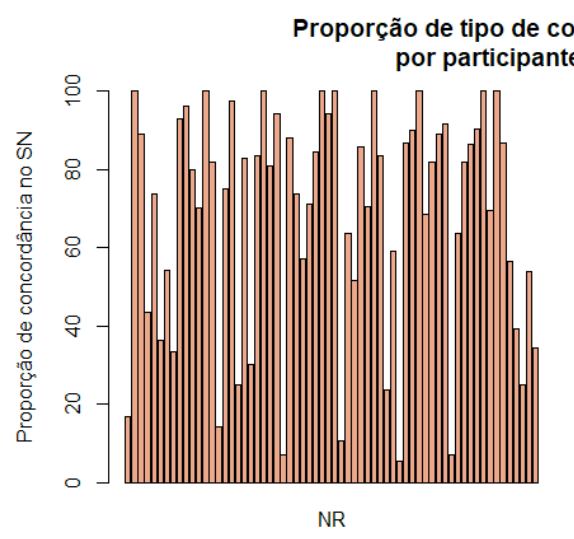

Tipo de Concordância no SN

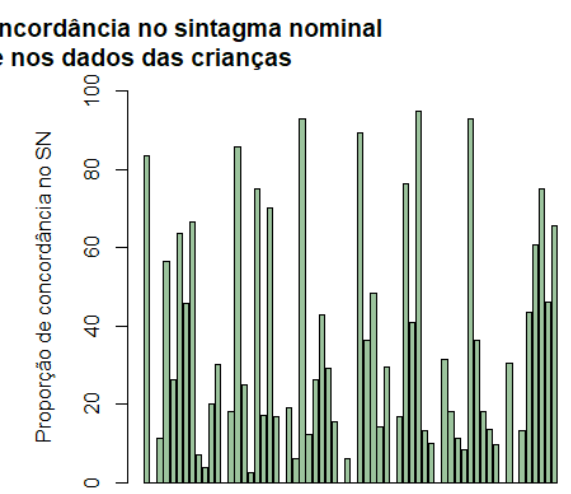

$\mathrm{R}$

Tipo de Concordância no SN

Figura 11 - Proporção de tipo de concordância entre sujeito e verbo por participante nos dados das crianças.

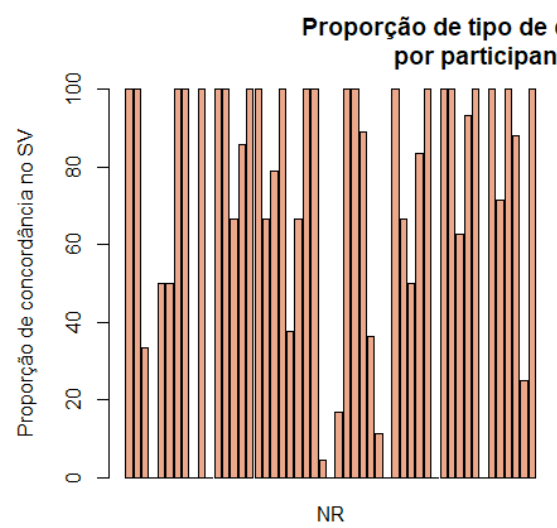

Tipo de Concordância no SV

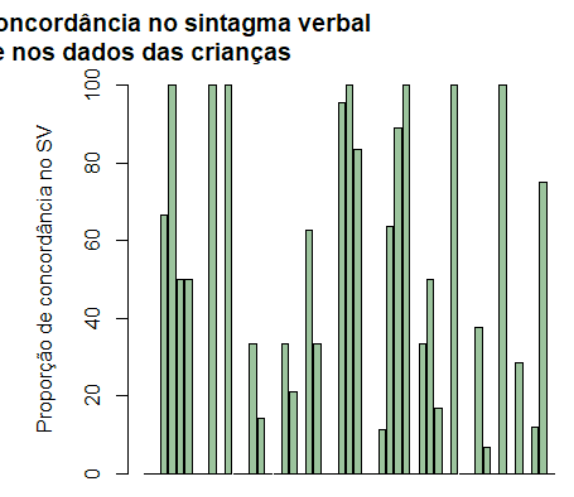

$\mathrm{R}$

O aspecto mais interessante identificado nos dados analisados diz respeito à diferença entre a variação encontrada para o SN e para o verbo. Os resultados obtidos sugerem que elas sejam de natureza distinta. Uma vez que a idade do participante não se mostrou um fator 
relevante para o tipo de concordância no $\mathrm{SN}$, mas se mostrou relevante para o tipo de concordância no verbo, interpretei a variação entre a presença/ausência da marca de plural no verbo como sendo um reflexo do processo de aquisição da língua, enquanto a variação na concordância nominal parece ser, na verdade, decorrente da aquisição de duas gramáticas pela criança. Na próxima seção, expande-se essa discussão a partir da proposta de competição de gramáticas (Yang, 2002).

\section{A aquisição da concordância de número em PB e a proposta de competição de gramáticas}

Relacionando os resultados expostos acima à proposta de competição de gramáticas de Yang (2002), entendo que estão ocorrendo dois processos distintos para a aquisição da concordância nominal e da concordância verbal em PB. Tomando como base o Modelo Variacional (Yang, 2002), teríamos três possíveis resultados para a aquisição da concordância de número em PB: (i) a criança poderia fazer uma regularização positiva, ou seja, ela poderia assumir que, no PB, o plural é expresso pela presença das marcas de plural explícitas em todos os itens flexionáveis da sentença; (ii) a criança poderia fazer uma regularização negativa, assumindo que, no PB, o plural é expresso pela presença da marca de plural em apenas um (ou alguns) dos itens flexionáveis da sentença (geralmente o D); (iii) a criança poderia assumir duas gramáticas: uma em que a noção de pluralidade é expressa por um padrão redundante de concordância, i.e., pela marcação de todos os elementos flexionáveis na sentença; e outra em que a noção de pluralidade é expressa por um padrão não redundante, ou seja, pela marcação de apenas alguns (ou um) dos elementos flexionáveis na sentença.

Assim, confrontando os resultados encontrados com os possíveis resultados previstos pelo modelo de Yang (2002), identifica-se que, para o SN, os dados parecem sugerir que ocorra o que é descrito em (iii) acima. Não há indicação de que a variação seja apenas parte do processo de aquisição da concordância de número pelas crianças testadas, uma vez que os dois padrões de concordância parecem se manter ao longo do desenvolvimento linguístico, já que participantes de todas as idades exibiram as duas formas em suas produções linguísticas (bem como os adultos que integraram o grupo controle). Já para a concordância verbal, os resultados sugerem que a variação observada seja de outra natureza. Os dados encontrados indicam que as crianças parecem percorrer o seguinte caminho durante a aquisição da concordância verbal: (i) inicialmente, a criança parece regularizar negativamente a concordância de número em suas produções - i.e., os verbos aparecem sem a marca de plural explícita; (ii) em seguida, parece haver um período em 
que duas gramáticas competem durante a aquisição; (iii) finalmente, a criança parece caminhar para uma regularização positiva da concordância de número em sua fala, exibindo ocorrências com a marca morfofonológica de plural explícita.

Desse modo, concluo que a aquisição da concordância de número pelas crianças brasileiras exibe percursos distintos para os sintagmas nominal e verbal, e que os dois processos devem ser analisados separadamente, como fenômenos distintos. Quase todas as crianças testadas no experimento descrito exibiram um comportamento individual variável, não indicando nem regularização negativa e nem regularização positiva para a presença/ausência das marcas de plural nos elementos que integram o SN. Esse resultado foi interpretado no sentido de que as crianças parecem estar, de fato, adquirindo os dois padrões de concordância para o SN. Seguindo o mecanismo proposto no Modelo Variacional (Yang, 2002), entende-se que duas gramáticas com padrões opostos para a realização de concordância no SN sejam recompensadas com base nos dados dispostos no input. Assim, seria possível que a criança adquira tanto uma gramática em que a marcação de plural nos itens do SN ocorre de maneira categórica, quanto uma gramática em que a presença da marca de plural é necessária apenas em alguns elementos (ou em um elemento) do SN. Conforme demonstrado pelos dados (cf. figura 11), não se pode afirmar o mesmo para a concordância verbal. Os participantes exibiram um comportamento menos variável, uma vez que a maioria dos participantes testados regularizou positiva ou negativamente a marcação da concordância de número no sintagma verbal.

Duas questões fundamentais não podem deixar de serem mencionadas antes de finalizar esta discussão. A primeira questão diz respeito ao tipo de verbo observado nas produções infantis e à própria tarefa de eliciação conduzida com as crianças testadas. Além do experimento realizado neste estudo ter funcionado melhor para a eliciação da concordância nominal, gerando mais dados de plural entre os itens do SN que entre sujeito e verbo, o tipo de verbo observado na fala dos participantes foi, majoritariamente, de cópula. Desse modo, é necessário que se analisem as ocorrências de plural com outros tipos de verbo na fala infantil, para que se verifique se os resultados estão de acordo com os encontrados aqui. O segundo ponto diz respeito à maneira como a expansão da proposta de Yang (2002) precisa ser realizada para que se sustente de maneira mais clara. Tendo-se em vista que a argumentação do autor é estabelecida em termos de marcação paramétrica, pensar quais parâmetros entrariam em jogo para a concordância nominal é um trabalho que se mostra necessário. Uma vez que, neste estudo, buscou-se desenvolver uma pesquisa muito mais experimental que teórica, esse ponto é um aspecto que não será 
desenvolvido aqui. Contudo, postular de que maneira a concordância nominal redundante e não redundante podem ser pensadas em termos de parâmetros é um desafio que deixo para trabalhos futuros.

\section{Considerações finais}

Neste trabalho, foram apresentados os resultados obtidos em um experimento de produção eliciada que objetivou analisar a realização da concordância de número na fala das crianças brasileiras. A discussão desenvolvida aqui foi embasada pela Teoria de P\&P (Chomsky, 1981) e pela proposta de competição de gramáticas, nos termos de Yang (2002). Nos dados analisados, o grupo (adulto vs. criança) foi um fator identificado como relevante: as crianças não só produziram mais concordância NR que os adultos, como produziram, de maneira geral, mais ocorrências com concordância NR que com concordância R. Indo de encontro à hipótese de trabalho estabelecida, os condicionadores nível socioeconômico e grau de escolaridade dos pais, medidos pelo tipo de escola frequentada pelo participante, não se mostraram relevantes para o padrão de concordância produzido pela criança. A saliência fônica do nome foi identificada como um fator relevante para o tipo de concordância no SN, mas no sentido oposto ao que era esperado: houve mais concordância não redundante em nomes considerados salientes que em nomes considerados não salientes. Esses dados vão de encontro ao que há na literatura acerca da influência desse fator sobre o tipo de concordância utilizado pelo falante (Naro; Lemle, 1976; Lemle; Naro, 1977; Naro, 1981; Naro; Scherre, 2006; Mendes; Oushiro, 2018 entre outros). Não é claro o que motivou esse resultado, mas, talvez, a frequência de uso das palavras que se referiam aos estímulos utilizados para a eliciação possa ter tido alguma influência sobre o desempenho infantil. Um experimento que contasse com palavras distintas ou com palavras inventadas poderia exibir resultados distintos para o fator em questão. Por fim, houve efeito de paralelismo formal entre a concordância utilizada no sujeito e a concordância verbal, com sujeitos com concordância redundante favorecendo a presença da marca de plural no verbo.

O ponto mais interessante e que se buscou destacar neste trabalho foi a diferença entre a variação observada nos âmbitos nominal e verbal. A idade do participante foi identificada como um efeito relevante apenas para a concordância verbal, e não para a concordância dentro do SN. Assim, foi proposto que a variação na concordância de número na fala infantil seja de natureza distinta para os dois sintagmas. No que diz respeito ao SN, a variação observada na fala infantil parece sugerir que as crianças, de fato, estejam adquirindo as duas formas em variação na língua. 
Já para a concordância entre sujeito e verbo, os resultados foram interpretados no sentido de que a variação entre a presença/ausência da marca de plural nas produções das crianças parece ser um reflexo do processo de aquisição. É importante reforçar que os verbos encontrados nos dados foram verbos de cópula. Assim, reconheço a necessidade de que mais estudos sejam realizados para que seja possível identificar se a análise proposta aqui pode ser estendida para outros tipos de verbo.

Naro e Scherre (2006) defendem que parece haver “(...) uma imposição, vinda de fora, de uma gramática categórica em cima da gramática natural variável do falante."12 (p. 120). Essa proposta destaca a importância de fatores externos sobre o fenômeno da Concordância Variável no PB. Visto que o uso da variante não redundante é estigmatizado na língua, fatores externos, como a escolarização, podem suprimir o uso de concordância NR nas produções linguísticas dos falantes adultos. Assim, assumindo a possibilidade de que mais de uma gramática estabilizada possa existir em um falante maduro, como proposto em Yang (2002), o estigma social relacionado a uma das formas em variação - no caso analisado aqui, a concordância não redundante - pode fazer com que o falante prefira e tenda a utilizar o padrão de prestígio com mais frequência, mesmo que, durante o processo de aquisição, tenha adquirido também a forma estigmatizada em uma gramática com formatação oposta. Deixo em aberto, para trabalhos futuros, que sejam identificados e estabelecidos quais parâmetros entrariam em jogo na aquisição da concordância nominal.

\section{Referências}

AVELAR, J. Gramática, competição e padrões de variação: casos com ter/haver e de/em no português brasileiro. Rev. Est. Ling., Belo Horizonte, v. 14, n. 2, p. 99-143, jun./dez. 2006.

BRANDÃO, S. F.; VIEIRA, S. R. A concordância nominal e verbal no Português do Brasil e no Português de São Tomé: uma abordagem sociolinguística. PAPIA, v. 22, p. 7-33, 2012.

CASTRO, A.; FERRARI-NETO, J. Um estudo contrastivo do PE e do PB com relação à identificação de informação de número no DP. Letras de Hoje. Porto Alegre, v. 42, n. 1, p.65-76, março, 2007.

CHOMSKY, N. Aspects of the Theory of Syntax. Cambridge, MA: MIT Press, 1965. . Lectures on government and binding. Dordrecht: Foris, 1981.

\footnotetext{
${ }^{12}$ É importante ressaltar que os autores se referem a gramáticas nos termos de Kroch (1989), e não nos termos de Yang (2002), conforme se utilizou neste trabalho.
} 
. Knowledge of Language: Its Nature, Origin and Use. New York: Praeger, 1986.

COELHO, I. L.; GÖRSKY, E. M.; MAY, G. H.; SOUZA, C. M. N. Sociolinguística. Florianópolis: LLV/CCE/UFSC, 2010.

COSTA, J.; FIGUEIREDO SILVA, M. C. Notes on nominal and verbal agreement in Portuguese. Rivista di Grammatica Generativa, Itália, v. 27, p. 19-29, 2002.

FINGER, I. Teorias de aquisição da linguagem. Florianópolis: Editora da UFSC, 2008.

GOMES, C. A.; PONTES, M. C. V; ALMEIDA, M. C. S.; ABREU, A. C. B. de. Variação e aquisição da flexão nominal e da flexão verbal. Revista Gragoatá. Niterói, n. 30, p. 39-54, 1. sem. 2011.

HENRY, A. Acquiring language from variable input: subject-verb agreement and negative concord in Belfast English. Linguistic Variation, 16. 131-150, 2016.

JAKUBOW, A. P. S. P. Language acquisition based on variable input: the case of number agreement in Brazilian Portuguese. 192f. Tese (Doutorado). Rio de Janeiro: PUC - Rio, 2018.

KATO, M. A. Sintaxe e aquisição na visão de Princípios e Parâmetros. Letras de Hoje, 102: 57-74, 1995.

A evolução da noção de parâmetros. DELTA, São Paulo, v. 18, n. 2, p. 309-338, 2002.

. A gramática do letrado: questões para a teoria gramatical. MARQUES, M. et al. (Orgs). Ciências da Linguagem: trinta anos de investigação e ensino. Braga: CEHUM (U. do Minho), p. 131145, 2005.

. Comparando o Português da América com o Português de Portugal e com outras línguas. Língua Portuguesa, Museu da Língua Portuguesa, 2006.

KATO, M. A.; DUARTE, M. E. L. Restrições na distribuição de sujeitos nulos no Português Brasileiro. Veredas (UFJF. Online), v. 18, p. 1-21, 2014.

$\mathrm{KROCH}, \mathrm{A}$. Reflexes of Grammar in Patterns of Language Change. Language Variations and Change, (1):199-244, 1989.

. Morphosyntactic variation, 1994. (Ms).

. Mudança Sintática. Tradução: Silvia Regina Cavalcante (UNICAMP). (2003): 2010. Disponível em: ftp://babel.ling.upenn.edu/facpapers/tony_kroch/papers/mudanca-sintatica.pdf Acesso em: 25/06/2019.

LEMLE, M.; NARO, A. J. Competências Básicas do Português. Relatório Final apresentado às instituições Fundação Ford e Movimento Brasileiro de Alfabetização (Mobral), 1977.

LESSA-DE-OLIVEIRA, A. S. C. Aquisição da linguagem e variação linguística. Estudos Linguísticos XXXIV, p. 409-414, 2005.

LIGHTFOOT, D. Language acquisition and language change. WIREs CognitiveScience, 1:677-684, 2010. 
LOPES, R. E. V. Estágios no processo de aquisição de número no DP do Português Brasileiro. Letras de Hoje, Porto Alegre, v.39, n.3, p.157-171, 2004.

MENDES, R. B. OUSHIRO, L. Variable number agreement in Brazilian Portuguese: an overview. Language and Linguistics Compass, John Wiley \& Sons, Inc, v. 9, n. 9, p. 358-368, 2015.

MILLER, K.; SCHMITT, C. Variable vs. Consistent Input: Comprehension of Plural Morphology and Verbal Agreement in Children. In: BRUCART, J. M.; GAVARRÓ, A.; SOLÀ, J. Merging Features: Computation, Interpretation and Acquisition. New York: Oxford University Press, 2009.

. Effects of variable input in the acquisition of plural in two dialects of Spanish. Lingua, 120 (5), p. 1178-1193, 2010. 261, 2012a.

. Variable Input and the Acquisition of Plural Morphology. Language Acquisition, 19:3, 223-

. Not All Children Agree: Acquisition of Agreement When The Input Is Variable. Language Learning and Development, v. 8, p. 255-277, 2012b.

MOLINA, D. S. L.; MARCILESE, M.; NAME, M. C. Ora está, ora não está: input variável e aquisição da flexão verbal de 3a pessoa do plural no PB. Matraga, v. 24, p. 288-309, 2017.

MOLINA, D. S. L. Aquisição da linguagem e variação linguística: um estudo sobre a flexão verbal variável na aquisição do PB. 279f. Tese (Doutorado). Juiz de Fora: UFJF, 2018.

NARO, A. J.; LEMLE, M. Syntactic diffusion. In: STEEVER, Sandord B. et alii (Eds.) Papers from the parasession on Diachronic Syntax. Chicago: Chicago Linguistic Society, p.221-241, 1976.

NARO, A. J. The social and structural dimensions of a syntactic change. LSA, Language, v. 57, p. 6398, 1981.

REIS, M. M. Aquisição da variação e mudanças na(s) gramática(s) das crianças: um olhar sobre a Concordância Variável no PB. 179f. Dissertação (Mestrado). Campinas: UNICAMP, 2020.

ROBERTS, I. Diachronic Syntax. Oxford: Oxford University Press, 2007.

SCHERRE, M. M. P.; NARO, A. J. Mudança sem mudança: a concordância de número no português brasileiro. SCRIPTA, Belo Horizonte, v. 9, n. 18, 107-129, 2006.

SIMIONI, L. Aquisição da concordância nominal de número: um estudo de caso. Revista de Estudos da Linguagem, Belo Horizonte, v. 14, n. 2, p. 539- 570, 2006.

YANG, C. D. Internal and external forces in language change. Language Variation and Change, v. 12, p. 231-250, 2000.

. Knowledge and Learning in Natural Language. New York: Oxford University Press, 2002.

456, 2004.

. Universal Grammar, statistics or both? Trends in Cognitive Sciences, v. 8, n. 10, p. 451. For and against frequencies. Journal of Child Language, 42(2), pp. 287-293, 2015a. 
Negative knowledge from positive evidence. Language, v. 91, n. 4, p. 938-953, 2015b.

A Formalist perspective on language acquisition. Linguistic Approaches to Bilingualism, 8(6), p. 665-706, 2018. 